\title{
A low-cost, low-density, and corrosion resistant AlFeMnSi compositionally complex alloy
}

\author{
S. P. O'Brien ${ }^{1,2}$, J. Christudasjustus $\mathbb{D}^{1,2}$, L. Esteves ${ }^{2}$, S. Vijayan ${ }^{3}$, J. R. Jinschek $\mathbb{D}^{3}$, N. Birbilis ${ }^{4}$ and R. K. Gupta $\mathbb{D}^{1,2 凶}$
}

A compositionally complex alloy was designed, consisting of equiatomic concentrations of four low-cost commodity elements (Al, $\mathrm{Fe}, \mathrm{Mn}$, and $\mathrm{Si}$ ). The alloy was characterized using scanning electron microscopy and energy-dispersive X-ray spectroscopy. The corrosion of the AlFeMnSi alloy, as evaluated using potentiodynamic polarization tests and electrochemical impedance spectroscopy in $0.6 \mathrm{M} \mathrm{NaCl}$ solution, was comparable with that of stainless steel (SS) 304L. Detailed X-ray photoelectron spectroscopy analysis was carried out, including the determination of high-resolution spectra and surface sputtering. In addition, scanning transmission electron microscopy was also used to study the surface film(s) developed after constant immersion. The AlFeMnSi alloy exhibited a unique form of 'passivity' that arises from the development of a silicon-rich surface film from dynamic incongruent dissolution.

npj Materials Degradation (2021)5:12; https://doi.org/10.1038/s41529-021-00158-5

\section{INTRODUCTION}

The development of metallic materials exhibiting high corrosion resistance at lower cost is necessary to meet the demand for materials utilized in advanced technologies. In terms of cost efficiency and overall sustainability, it is further beneficial if such materials result from the utilization of recycled commodity metals, such as $\mathrm{Al}, \mathrm{Fe}, \mathrm{Mn}$, etc., along with their principal impurities (that may include $\mathrm{Si}$, copper (Cu), Zn, C, etc.) $)^{1}$.

The typical corrosion resistant alloys (CRAs), such as stainless steels (SS) and nickel (Ni) based alloys, rely on their ability to form and maintain a thermodynamically stable passive film for corrosion resistance ${ }^{2}$. Therefore, CRAs are nominally comprised of a high concentration of elements that provide corrosion resistance (such as chromium (Cr) in SS), which limits the selection of alloy compositions for corrosion resistance, but also dictates alloy properties and costs. For example, corrosion resistance of SS depends upon the $\mathrm{Cr}$ and molybdenum (Mo) content, whereby $\mathrm{Cr}$ facilitates the formation of $\mathrm{Cr}$-rich passive film ${ }^{2}$, and Mo helps in increasing pitting resistance ${ }^{3}$, whilst additional alloying elements such as $\mathrm{Ni}$ are also often employed.

Development of the CRAs with properties beyond conventional limits has to date been hindered by a hitherto limited understanding of the structure/processing/property/performance relationship over various length scales, along with a lack of manufacturing technologies to engineer desired microstructures, whilst exploration of a finite compositional space was traditionally confined to alloys that could be readily cast. Recent research into so-called high entropy alloys, or more generally, compositionally complex alloys (CCAs) has revealed both a broad and previously unexplored compositional space in the context of metallic alloys. CCAs, comprised of four or more principal elements in near equiatomic ratios, are emerging alloys ${ }^{4,5}$. Many CCAs, depending upon composition and structure, have been reported to possess exceptional properties that include super plasticity ${ }^{6}$, high fracture toughness ${ }^{7}$, high strength, and high resistance to environmental degradation in aqueous and high temperature environments ${ }^{8}$.
Most corrosion resistant CCAs reported to date contain a high $\mathrm{Cr}$ concentration, and therefore the mechanism for corrosion resistance has been proposed to be similar to that reported for $\mathrm{Fe}-\mathrm{Cr}$ - and $\mathrm{Ni}-\mathrm{Cr}$-based alloys ${ }^{9}$. A conventional pitting resistance equivalent number type of approach for designing corrosion resistant CCAs has been proposed by several researchers ${ }^{10-12}$. This conventional approach, however, would result in CCAs with high cost and high density and inhibit exploitation of the full potential of CCAs-which have been noted as being inherently corrosion resistant (in spite of complex elemental compositions and heterogeneous microstructures) $)^{9,13}$. The cost and density of 115 CCAs (studied in $0.6 \mathrm{M} \mathrm{NaCl}$ ) reported in literature are presented in Supplementary Table 1 (Supplementary Notes 1), which illustrates the high densities and high costs of current CCAs. Only one CCA has an elemental cost below SS 316L, and the average cost of a CCA is $\sim 16 \$ / \mathrm{kg}$ (in USD). The average theoretical density is $\sim 7 \mathrm{~g} /$ $\mathrm{cm}^{3}$, with a few alloys, which are high in aluminum content, ranging as low as $\sim 5 \mathrm{~g} / \mathrm{cm}^{3}$.

A comprehensive consideration regarding the properties typical of CCAs along with the characteristics desired in CRAs may facilitate developing concepts regarding the targeted development of CCAs with corrosion resistance as the goal. The alloy-environment interface is a complex and dynamic system during corrosion, and a complete understanding of the interfaces between the environment (electrolyte), the surface film and the underlying metal interfaces, is still an area of active research. Subtle changes in a surface film and underlying alloy are known to strongly influence corrosion resistance. For example, the high pitting resistance of high-energy ball milled and sputter deposited $\mathrm{Al}$ alloys has been attributed to the doping of $\mathrm{Al}_{2} \mathrm{O}_{3}$ surface films with alloying elements ${ }^{14}$. In addition, increasing $\mathrm{Al}$ content in $\mathrm{Al}_{x} \mathrm{CoCrFeNi}$ alloys deteriorated the corrosion resistance, which was attributed to lower $\mathrm{Cr}$ content and formation of a Al-rich (i.e., $\mathrm{Cr}$ depleted) phase ${ }^{15-17}$. However, increasing $\mathrm{Al}$ content in $\mathrm{Al}_{x} \mathrm{CrFeMoV}$ produced a $\mathrm{V}-, \mathrm{Cr}-$, Mo-rich secondary phase (i.e., $\mathrm{Al}$ depleted) and reduced the passive current density, thereby

\footnotetext{
Department of Materials Science and Engineering, North Carolina State University, Raleigh, NC, USA. ${ }^{2}$ Department of Chemical, Biomolecular and Corrosion Engineering, The University of Akron, Akron, OH, USA. ${ }^{3}$ Department of Materials Science and Engineering, The Ohio State University, Columbus, OH, USA. ${ }^{4}$ College of Engineering \& Computer Science, Australian National University, Acton, ACT, Australia. ${ }^{凶}$ email: rkgupta2@ncsu.edu
} 
(a)

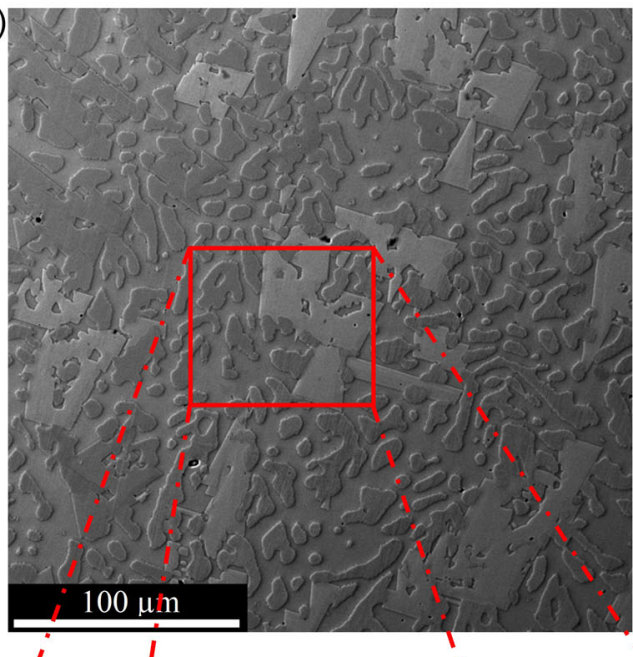

(c)
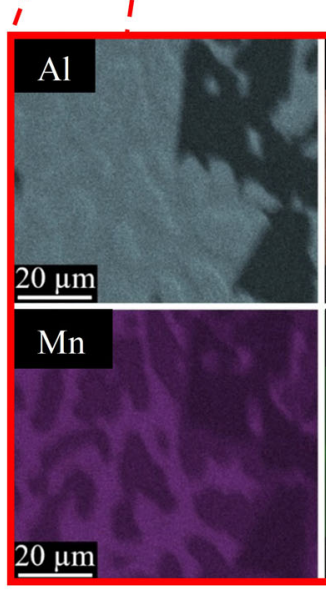

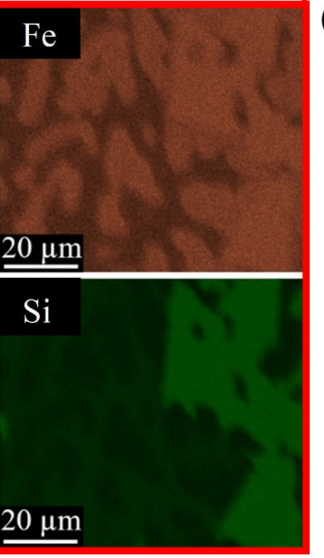

(b)

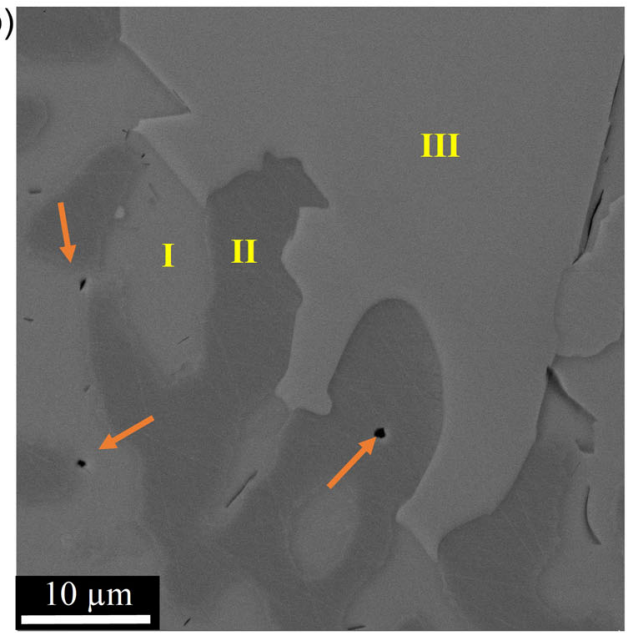

(d)

\begin{tabular}{|c|c|c|c|}
\hline Element & I (at. \%) & II (at. \%) & III (at. \%) \\
\hline Al & $20.3( \pm 0.7)$ & $20.8( \pm 1.1)$ & $9.8( \pm 0.8)$ \\
\hline Fe & $25.5( \pm 0.8)$ & $35.9( \pm 1.4)$ & $36.2( \pm 2.5)$ \\
\hline Mn & $39.1( \pm 1.3)$ & $30.3( \pm 0.8)$ & $27.5( \pm 2.1)$ \\
\hline Si & $15.1( \pm 0.7)$ & $13.0( \pm 1.3)$ & $26.5( \pm 1.3)$ \\
\hline
\end{tabular}

Fig. 1 Microstructure of the AIFeMnSi alloy. a Backscattered electron (BSE) scanning electron microscopy (SEM) image (20 kV accelerating voltage) of as-cast AIFeMnSi, b high-magnification BSE image, c SEM energy-dispersive X-ray spectroscopy (EDXS) map corresponding to the highlighted region in $\mathbf{a}$, and $\mathbf{d}$ table indicating measured elemental composition of all phases (I-III) in as-cast AIFeMnSi (based on EDXS point analysis).

improving the corrosion resistance ${ }^{11}$. The modification of $\mathrm{Al}$ content in these two alloys and their resultant corrosion trends further illustrates how the corrosion resistance not only depends on the composition but also on the microstructure of the alloy.

Recently, Birbilis and coworkers have reported a fourcomponent CCA, AITiVCr, which exhibited corrosion resistance superior to SS $304 \mathrm{~L}^{18-20}$ and indeed, characteristics typical of highly CRAs. Surface analysis, using X-ray photoelectron spectroscopy (XPS), indicated the surface film was enriched in oxidized $\mathrm{Al}$, owing to incongruent dissolution of the AITiVCr alloy. In addition, the surface film was also comprised of a mixture of oxidized forms of the other alloying elements (i.e., $\mathrm{Ti}, \mathrm{V}, \mathrm{Cr}$ ), however, in proportions different to the bulk alloy composition, along with unoxidized metal. A later study, using atomic emission spectroelectrochemistry, supported incongruent dissolution and preferential dissolution of $\mathrm{Al}$ in $\mathrm{Al}_{1.5} \mathrm{TiVCr}^{21}$. Such results have revealed the possibility to develop CCAs where the surface film may not be composed of well-known passivating elements, such as $\mathrm{Cr}$. Moreover, given that CCA compositions are complex and distinct, the possibility of forming a complex film containing several elements is feasible ${ }^{22}$. Therefore, studying the formation of the surface film on CCAs and exploring their corrosion resistance warrants focused study.

In this study, a corrosion resistant CCA was produced, based on four principal elements in equiatomic concentrations (i.e., $\mathrm{Al}, \mathrm{Fe}, \mathrm{Mn}$, $\mathrm{Si})$, and the surface film was studied using various state-of-the art materials characterization techniques, including scanning electron microscopy (SEM), scanning transmission electron microscopy (STEM), energy-dispersive X-ray spectroscopy (EDXS), and XPS.

\section{RESULTS AND DISCUSSION}

\section{Alloy microstructure}

The low-magnification backscattered electron (BSE) SEM image (Fig. 1a) of the AlFeMnSi alloy, produced by arc melting, suggested the presence of three different phases, which are shown clearly in the high-magnification BSE image (Fig. 1b). Visible pores, marked by arrows in Fig. $1 b$, formed in the arc melting process. An EDXS area map, showing the distribution of the four elements ( $\mathrm{Al}, \mathrm{Fe}$, $\mathrm{Mn}, \mathrm{Si})$ within the alloy, is presented in Fig. 1c. Elemental distribution in each phase, determined using the point analysis, is tabulated in Fig. 1d. The composition values presented in Fig. 1d are an average of more than 28 measurements for each phase. Most notably, Phases I and II were relatively rich in Al, while lean in $\mathrm{Si}$, compared to Phase III, which, in contrast, was rich in Si and lean in Al. The crystal structures of the three phases could not be determined and is part of the future work.

\section{Hardness and elemental cost}

Vickers hardness testing was performed on the individual phases. Phases I, II, and III had the hardness of $1032( \pm 17), 952( \pm 13)$, and 
(a)

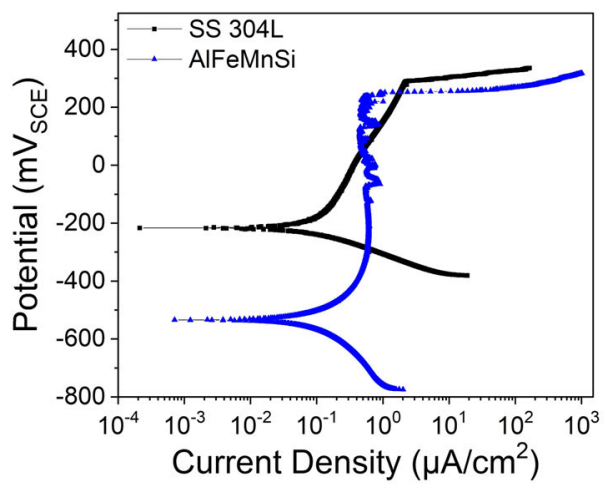

(c)

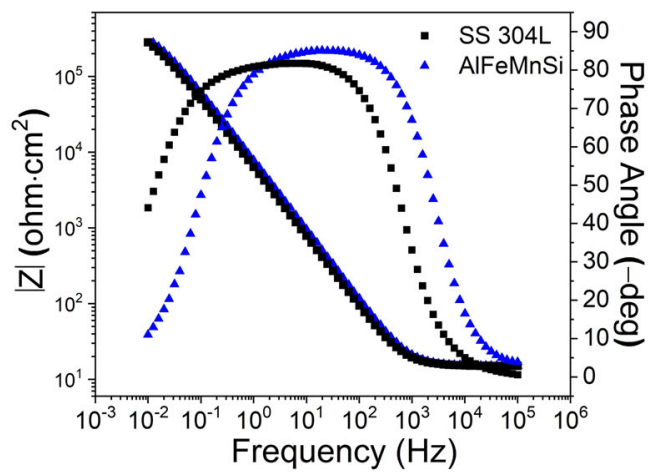

(b)

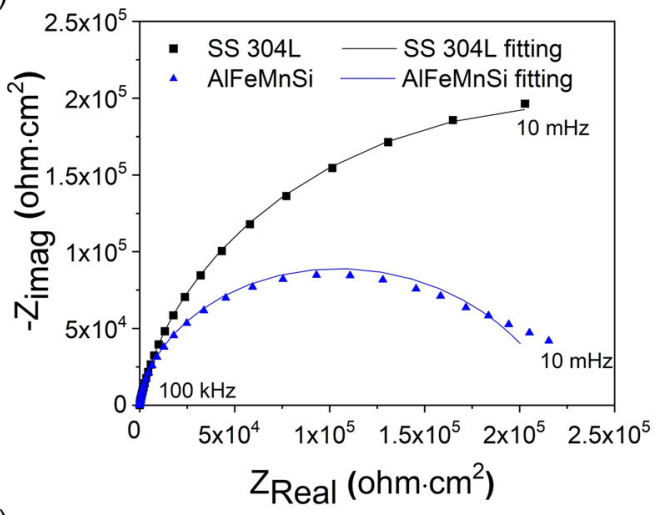

(d)

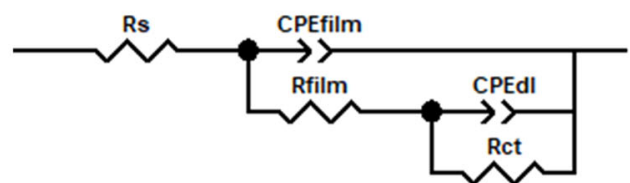

Fig. 2 Electrochemical corrosion performance of SS 304L and the AlFeMnSi alloy. a Potentiodynamic polarization curves collected using a potential sweep rate of $0.167 \mathrm{mV} / \mathrm{s}$. b Nyquist diagram showing the comparison of the experimental data and the simulated data. $\mathbf{c}$ Bode plots for the AIFeMnSi alloy and SS $304 \mathrm{~L}$ in $0.6 \mathrm{M} \mathrm{NaCl}$. d The electrical equivalent circuit of the system.

$1206( \pm 59) \mathrm{HV}$, respectively. The standard deviation is attributed to the microstructure heterogeneity. The theoretical density of the AlFeMnSi CCA is $4.5 \mathrm{~g} / \mathrm{cm}^{3}$ 23, which is comparable with the density of $\mathrm{Ti}\left(4.5 \mathrm{~g} / \mathrm{cm}^{3}\right)$ and is significantly lower than the density of austenitic SS $304 \mathrm{~L}\left(8 \mathrm{~g} / \mathrm{cm}^{3}\right)$. The elemental cost of the alloy, determined using a 50-year average price of individual elements $^{24}$, was $1.18 \$ / \mathrm{kg}$, which is notably lower than commonly used CRAs, such as SS $304 \mathrm{~L}(2.20 \$ / \mathrm{kg})$ or SS $316 \mathrm{~L}(3.28 \$ / \mathrm{kg})$ or other CCAs (presented in Supplementary Table 1).

\section{Electrochemical testing}

Typical potentiodynamic polarization curves (PDP) for the AlFeMnSi alloy (and SS 304L for comparison) in $0.6 \mathrm{M} \mathrm{NaCl}$ solution are presented in Fig. 2a and electrochemical parameters derived from the PDP are presented in Table 1. The AlFeMnSi alloy, along with SS 304L, exhibited spontaneous passivity. The corrosion potential $\left(E_{\text {corr }}\right)$ of the AIFeMnSi alloy was less noble than SS 304L, yet the breakdown potential $\left(E_{\mathrm{b}}\right)$ of the two alloys were similar resulting in a larger passive window $\left(E_{\mathrm{pw}}\right)$ for the AlFeMnSi alloy. While the AIFeMnSi alloy had a large deviation in the breakdown potential which was attributed to crevice corrosion. The corrosion current density $\left(i_{\text {corr }}\right)$ and overall passive current density for the two alloys were similar.

Nyquist and Bode plots for the AlFeMnSi alloy and the SS 304L in $0.6 \mathrm{M} \mathrm{NaCl}$ solution are shown in Fig. $2 b, c$, respectively. The Bode plot (Fig. 2c) exhibited a similar impedance |Z| vs. frequency response indicating a similar corrosion resistance between the AlFeMnSi alloy and SS 304L. Electrochemical impedance spectroscopy (EIS) results were fitted using the electrical equivalent circuit, as depicted in Fig. $2 \mathrm{~d}$. The solution resistance $\left(R_{\mathrm{s}}\right)$ was estimated at a high frequency $(100 \mathrm{kHz}), R_{\text {film }}$ and $\mathrm{CPE}_{\text {film }}$ represent the resistance and constant phase element (CPE) of the passive film, and $R_{\mathrm{ct}}$ and $C P E_{\mathrm{dl}}$ are the charge transfer resistance and double layer $C P E$, respectively, at low frequency. The CPEs were used to describe the frequency dependence of the nonideal capacitive behavior. When $n$ (the fractional exponent) equals 1 , a CPE simplifies to a capacitor, when $n$ equals 0 , a CPE represents a pure resistor, and when $n$ equals 0.5 , a CPE behaves as a Warburg impedance element ${ }^{25}$. The simulated data show good coincidence with the experimental systems, that is, fittings for the impedance data were performed using low $x^{2}$ values. Results (i.e., parameters extracted from the fitting) are shown in Table 1. The polarization resistance $R_{\mathrm{p}}$ (i.e., corrosion resistance) is theoretically equal to the sum of $R_{\mathrm{ct}}$ and $R_{\mathrm{film}}$, which are obtained from the fitting procedure. Accordingly, SS 304L exhibits slightly superior polarization resistance, but on the same order of magnitude as the AlFeMnSi alloy.

\section{Immersion testing}

In Fig. 3, SEM images of the AIFeMnSi alloy and SS 304L after 2-week immersion in $0.6 \mathrm{M} \mathrm{NaCl}$ solution revealed localized corrosion in the AlFeMnSi alloy as well as in SS 304L. For the AIFeMnSi alloy, corrosion occurred in all three phases, however, with more visible damage in Phases I and II, as highlighted in Fig. 3a. It should be noted again that Phase III contains the highest Si content and the lowest Al content. Dark spots, indicated by orange arrows in Fig. 3a, appear to be caused by localized corrosion in the pores present in the as-cast alloy (Fig. 1). Pitting corrosion, indicated by green arrows, on the surface of SS 304L was visible (Fig. 3b). Comparing the two alloys, the amount and depth of pitting corrosion on SS 304L may be more detrimental than the corrosion of the AlFeMnSi CCA (excluding corrosion of the pores). 


\section{Surface analysis by XPS}

XPS was performed to determine the chemical composition of the passive film developed after $24 \mathrm{~h}$ immersion of the AlFeMnSi alloy in $0.6 \mathrm{M} \mathrm{NaCl}$ solution. It should be noted SEM images $(5 \mathrm{kV}$ accelerating voltage, Supplementary Fig. $6 \mathrm{~b}$ ) of the AlFeMnSi alloy after $24 \mathrm{~h}$ immersion in $0.6 \mathrm{M} \mathrm{NaCl}$ revealed minimal corrosion damage, with more pronounced damage near preexisting pores. XPS high-resolution spectra scans, conducted after regular intervals of sputtering, revealed the composition of the surface film along the depth profile, as seen in Fig. 4a. The surface film, at sputtering time 0 , contained oxygen along with a majority of $\mathrm{Si}$ (17.2 at.\%) and $\mathrm{Al}$ (11.5 at.\%), and a minority of Fe (6.8 at.\%) and $\mathrm{Mn}$ (3.9 at.\%). After sputtering for $90 \mathrm{~s}$, the oxygen concentration decreased significantly, and the atomic concentration of the alloying elements increased. Such a decrease in oxygen content after $90 \mathrm{~s}$ of sputtering indicates an approximate surface film thickness of $10 \mathrm{~nm}$ (based on pure $\mathrm{SiO}_{2}$ sputtering where $30 \mathrm{~s}$ of sputtering is equivalent to $3.25 \mathrm{~nm}$ ). A recently reported $C C A$, AICrTiV, possessed an oxygen concentration above 20 at.\% after $60 \mathrm{~min}$ of sputtering due to a reactive surface spontaneously oxidizing upon sputtering ${ }^{20,21}$. Comparatively, the AlFeMnSi alloy exhibited a similar behavior but with a less reactive surface (3.7 at. $\%$ oxygen after $15 \mathrm{~min}$ of sputtering).

Oxidation states, oxidized or unoxidized, of the elements were determined using high-resolution XPS spectra scans (found in Supplementary Notes 2 along with chemical states) and are presented in Fig. $4 \mathrm{~b}$ as relative fractions of unoxidized element and corresponding oxidized species-determined from peak fitting Fig. 4c represents the atomic percentage of oxidized and unoxidized species (application of multiplying the total atomic concentration (Fig. 4a) with the relative fraction (Fig. 4b)). The top of the surface film ( $0 \mathrm{~s}$ of sputtering) was comprised of oxidized $\mathrm{Si}$ (12.9 at.\% $\mathrm{Si}^{\mathrm{x}+}$ ) and $\mathrm{Al}\left(7.7\right.$ at.\% $\left.\mathrm{Al}^{\mathrm{x}+}\right)$, followed by small amounts of oxidized $\mathrm{Fe}\left(2.7\right.$ at. $\left.\% \mathrm{Fe}^{\mathrm{x}+}\right)$ and $\mathrm{Mn}\left(1.6\right.$ at. $\left.\% \mathrm{Mn}^{\mathrm{x}+}\right)$. In addition, unoxidized elements (3.8 at.\% Al, 4.1 at.\% Fe, 2.3 at.\% $\mathrm{Mn}$ and 4.3 at.\% Si) were also detected. These unoxidized elements may belong to the substrate depending on the thickness of the surface film on each phase; however, the possibility of unoxidized elements present inside the surface film should not be disregarded. As sputtering was performed, $\mathrm{Al}^{\mathrm{x}+}$ enrichment was discovered at a time of $30 \mathrm{~s}$ of sputtering (Fig. 4b, c).

Furthermore, potentiostatic surface conditioning and subsequent surface characterization was utilized to obtain a better understanding of the surface film formed on the AIFeMnSi alloy by isolating discrete conditions selected from the PDP curve (Fig. 2a). Potentiostatic holds were performed in the cathodic region $\left(-700 \mathrm{mV}_{\mathrm{SCE}}\right.$ for $\left.1 \mathrm{~h}\right)$, passive region $\left(-250 \mathrm{mV}_{\mathrm{SCE}}\right.$ for $\left.1 \mathrm{~h}\right)$, and transpassive region $\left(+400 \mathrm{mV}_{\mathrm{SCE}}\right.$ for $\left.10 \mathrm{~min}\right)$ of the AIFeMnSi alloy in $0.6 \mathrm{M} \mathrm{NaCl}$. XPS was conducted on the surface film following potentiostatic conditioning followed by SEM imaging (outside of the sputtered area).

Figure 5 illustrates the XPS characterization of the cathodic region, and the results follow a similar trend as observed in the specimen after $24 \mathrm{~h}$ immersion (Fig. 4). The top of the surface film is rich in $\mathrm{Si}$ and $\mathrm{Al}$ followed by minor amounts of Fe and Mn (Fig. 5a). As seen in Fig. $5 \mathrm{~b}$, the fraction of oxidized species decreased with increased sputtering time while the fraction of unoxidized species increased. $\mathrm{Al}^{\mathrm{x}+}$ enrichment was identified at $30 \mathrm{~s}$ of sputtering, while unoxidized and oxidized species were identified in the surface film (Fig. 5b). The surface film is comprised primarily of oxidized $\mathrm{Si}$, followed by oxidized $\mathrm{Al}$ and small amounts of the other species (Fe and $\mathrm{Mn}$, see Fig. 5c). Compared to the $24 \mathrm{~h}$ immersion specimen, the cathodic region $\left(-700 \mathrm{mV}_{\mathrm{SCE}}\right)$ had a higher concentration of total oxidized species after $60 \mathrm{~s}$ of sputtering (Figs. $4 \mathrm{a}$ and $5 \mathrm{a}$ ). The concentration of unoxidized species increased with sputtering time. Following SEM imaging, minimal localized dissolution was revealed after potentiostatic conditioning for $1 \mathrm{~h}$ at $-700 \mathrm{mV}_{\text {SCE }}$ (Supplementary Notes 3 ). 
(a)

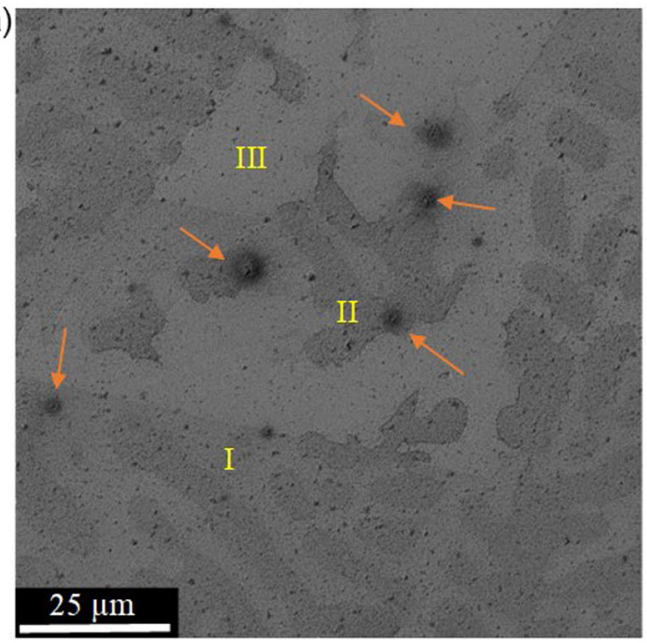

(b)

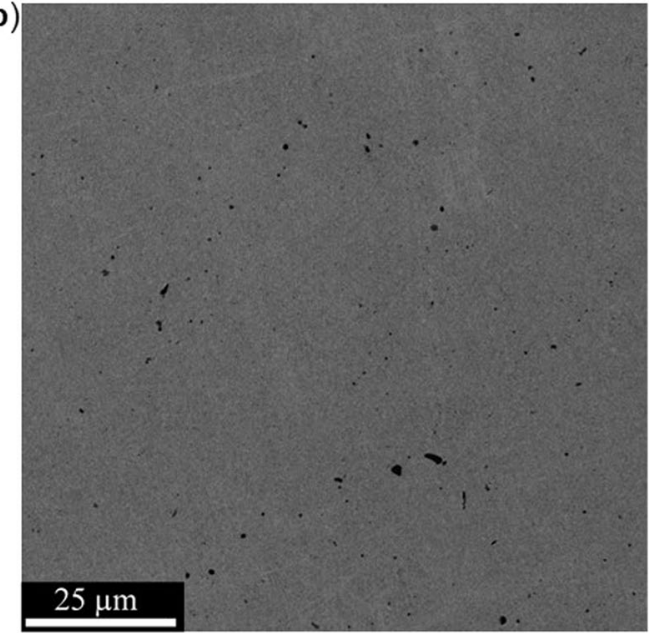

Fig. 3 BSE-SEM images post 2-week immersion in $\mathbf{0 . 6} \mathrm{M} \mathrm{NaCl}$ of SS $304 \mathrm{~L}$ and the AlFeMnSi alloy. BSE-SEM images (5 kV accelerating voltage) after 2-week immersion in $0.6 \mathrm{M} \mathrm{NaCl}$ of a the AlFeMnSi alloy (arrows point toward pores) and b SS 304L.

(a)

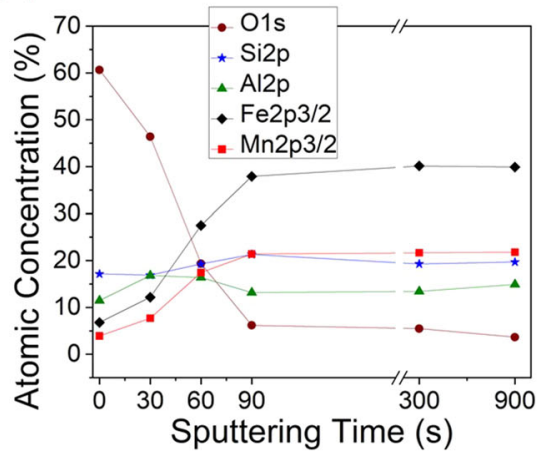

(b)

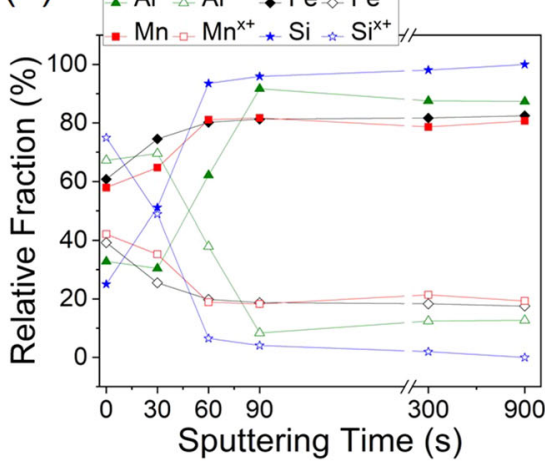

(c) $\triangle \mathrm{Al} \triangle \mathrm{Al}^{\mathrm{x}+} \cdot \mathrm{Fe} \diamond \mathrm{Fe}^{\mathrm{x}+}$

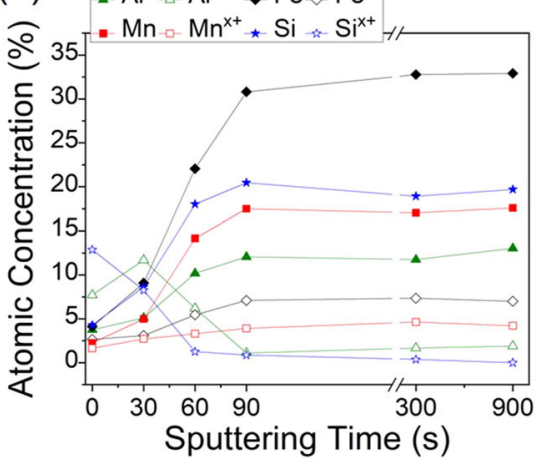

Fig. 4 XPS of the AlFeMnSi surface after $24 \mathrm{~h}$ immersion in $\mathbf{0 . 6} \mathrm{M} \mathrm{NaCl}$. Distribution of elements as a function of sputtering time determined by XPS following $24 \mathrm{~h}$ immersion of the AIFeMnSi alloy in $0.6 \mathrm{M} \mathrm{NaCl}$ : a atomic concentration, $\mathbf{b}$ relative fraction of oxidized element to corresponding unoxidized metal species, and c atomic concentration of oxidized and unoxidized species.

(a)

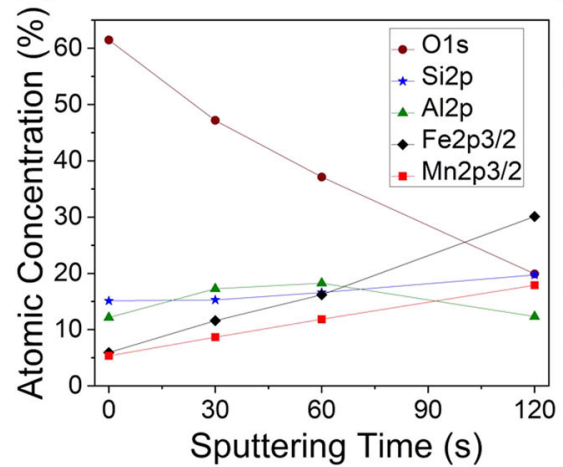

(b)

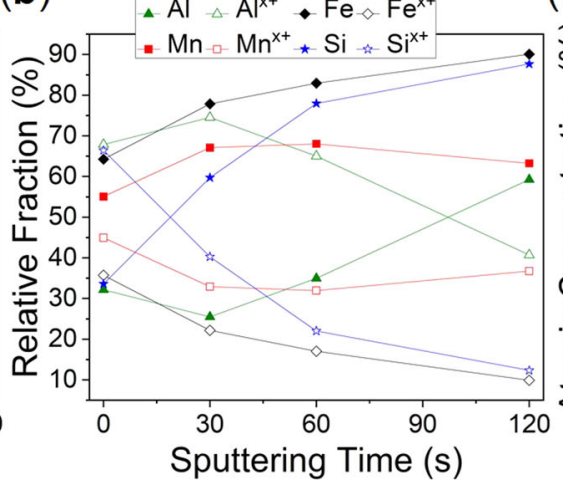

(c)

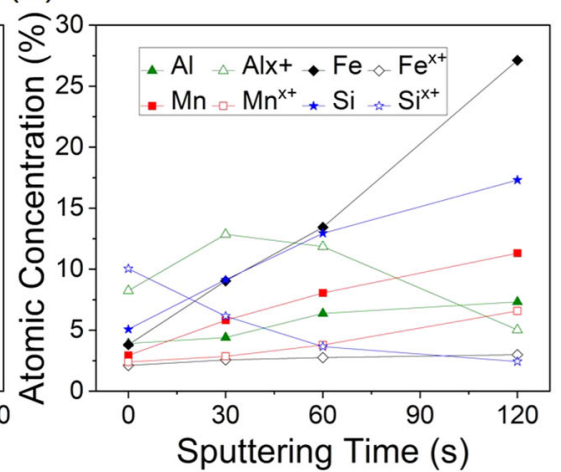

Fig. $5 \mathrm{XPS}$ of the AlFeMnSi surface after potentiostatic conditioning for $\mathbf{1} \mathbf{h}$ at $-\mathbf{7 0 0} \mathbf{m V} \mathrm{VCE}_{\mathrm{SC}}$ in $\mathbf{0 . 6} \mathbf{M}$ NaCl. Distribution of elements as a function of sputtering time determined by XPS following potentiostatic conditioning for $1 \mathrm{~h}$ at $-700 \mathrm{mV}$ SCE of the AlFeMnSi alloy in $0.6 \mathrm{M}$ $\mathrm{NaCl}$ : a atomic concentration, $\mathbf{b}$ relative fraction of oxidized element to corresponding unoxidized metal species, and $\mathbf{c}$ atomic concentration of oxidized and unoxidized species.

Figure 6 exhibits the XPS results after potentiostatic conditioning for $1 \mathrm{~h}$ at $-250 \mathrm{mV}_{\mathrm{SCE}}$, which is in passive region. The top of the surface film was comprised of primarily Si, followed by smaller concentrations of $\mathrm{Al}, \mathrm{Fe}$, and $\mathrm{Mn}$ (Fig. 6a). The fraction of the oxidized species decreased overall with sputtering time, except an enrichment of $\mathrm{Al}^{\mathrm{x}+}$ ratio at $60 \mathrm{~s}$, and the fractions of unoxidized species increased (Fig. 6b). In case of the Si-rich surface film, the majority is composed of $\mathrm{Si}^{\mathrm{x}+}$ (Fig. 6c), with the remainder a 
(a)

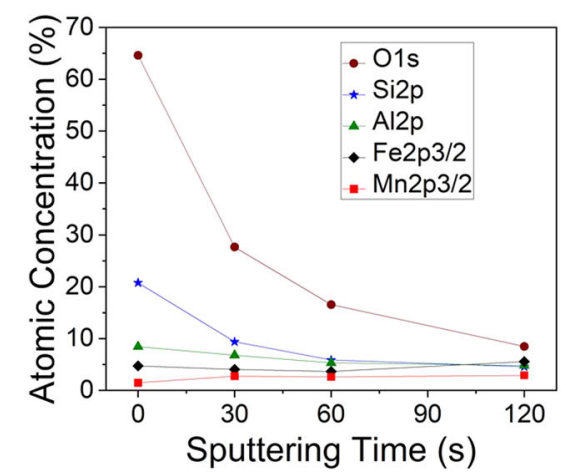

(b)

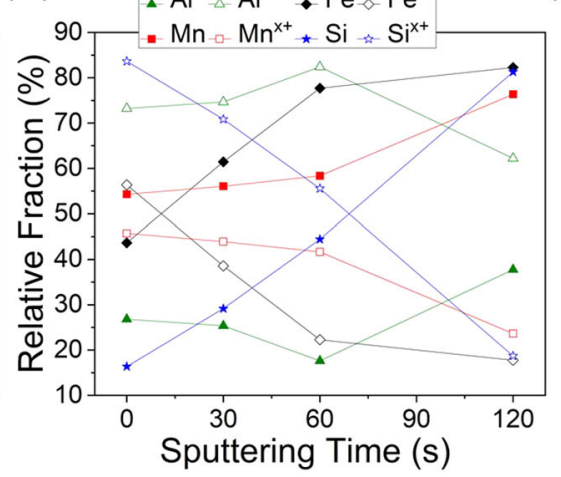

(c)

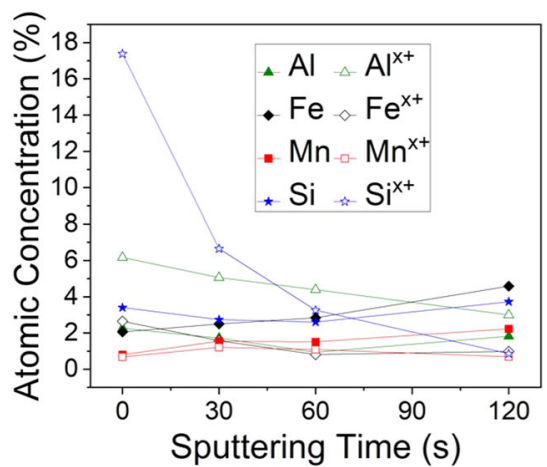

Fig. 6 XPS of the AIFeMnSi surface after potentiostatic conditioning for $\mathbf{1} \mathbf{h}$ at $-\mathbf{2 5 0} \mathbf{m V}_{\mathrm{SCE}}$ in $\mathbf{0 . 6} \mathbf{M} \mathbf{~ N a C l}$. Distribution of elements as a function of sputtering time determined by XPS following potentiostatic conditioning for $1 \mathrm{~h}$ at $-250 \mathrm{mV} \mathrm{SCE}_{\text {S }}$ of the AlFeMnSi alloy in $0.6 \mathrm{M}$ $\mathrm{NaCl}$ : a atomic concentration, $\mathbf{b}$ relative fraction of oxidized element to corresponding unoxidized metal species, and $\mathbf{c}$ atomic concentration of oxidized and unoxidized species.

(a)

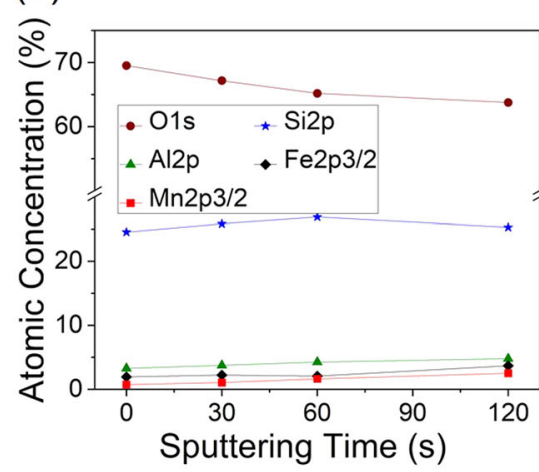

(b)

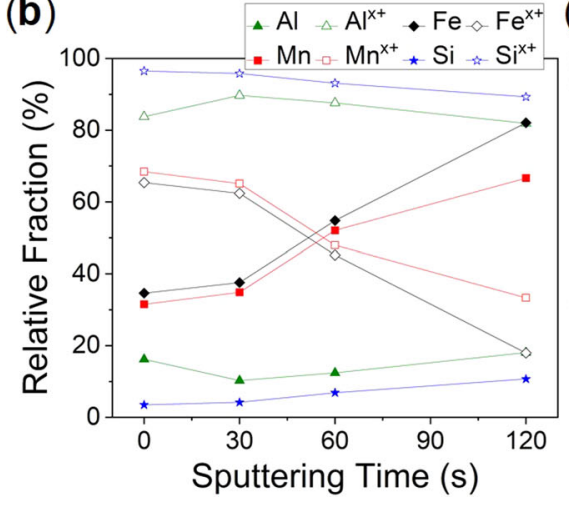

(c)

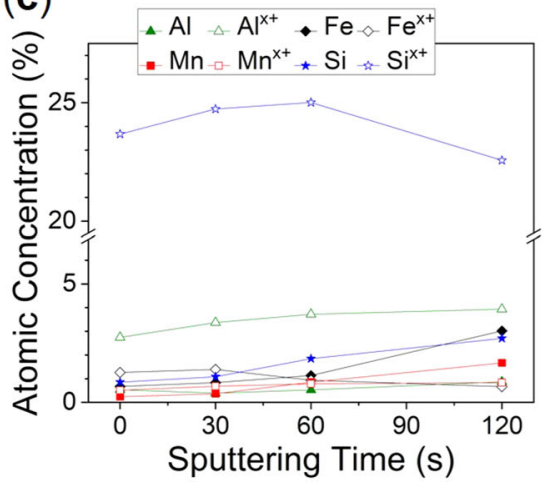

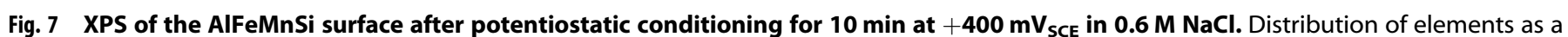

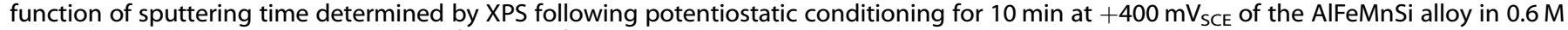

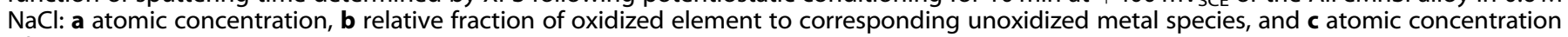
of oxidized and unoxidized species.

mixture of oxidized and unoxidized species. The content of total oxidized species at $60 \mathrm{~s}$ sputtering was less than prior results for the potentiostatic hold at $-700 \mathrm{mV}_{\mathrm{SCE}}$ and $24 \mathrm{~h}$ immersion, indicating a thinner surface film thickness. The concentration of unoxidized $\mathrm{Al}$ and $\mathrm{Si}$ indicates enrichments in the top of the surface film ( $0 \mathrm{~s}$ sputtering), where the concentration decreased and then increased with longer sputtering time (Fig. 6c). The enrichment is in strong contrast to the expected general trend of increased unoxidized species following removal of surface film and may suggest the presence of unoxidized species in the surface film. SEM imaging of the specimen after potentiostatic conditioning in the passive region showed no apparent localized dissolution (Supplementary Notes 3).

Figure 7 shows XPS results from the AIFeMnSi alloy specimen that was potentiostatically conditioned in the transpassive region $\left(+400 \mathrm{mV}_{\mathrm{SCE}}\right)$ in $0.6 \mathrm{M} \mathrm{NaCl}$ for $10 \mathrm{~min}$. The surface film is primarily comprised of $\mathrm{Si}$ and a marginal content of the remaining elements of the AlFeMnSi alloy (Fig. 7a). The fraction of oxidized species decreased with sputtering time, while the fraction of unoxidized species increased with sputtering time, except for the $\mathrm{Al}^{\mathrm{x}+}$ fraction enrichment at $30 \mathrm{~s}$ of sputtering (Fig. 7b). The oxide primarily consists of 23.7 at.\% $\mathrm{Si}^{\mathrm{x}+}$ (Fig. 7c); the concentration of $\mathrm{Si}^{\mathrm{x}+}$ was slightly enriched and then decreased after $60 \mathrm{~s}$ of sputtering. The concentration of oxidized $\mathrm{Al}$ and $\mathrm{Mn}$ increased with sputtering time, while oxidized Fe decreased with sputtering time. Similar to the $24 \mathrm{~h}$ immersion and the cathodic region, the concentration of unoxidized species in the transpassive region increased with sputtering time, which is expected when approaching the alloy's substrate from the surface film.

The BSE-SEM image in Fig. 8a revealed localized dissolution after potentiostatic conditioning in the transpassive region for $10 \mathrm{~min}$. The dissolution damage appears to congregate around Phase III. Due to the large amount of damage, an additional potentiostatic hold was conducted at $+400 \mathrm{mV}_{\mathrm{SCE}}$ for $30 \mathrm{~s}$, as seen in Fig. $8 \mathrm{~b}$. Accelerated localized dissolution was found at the interface between Phase II and III, while undercutting of Phase II is observed. The initiation of dissolution at the interface is not yet well understood but may be similar to that observed in SS 303 around $\mathrm{MnS}$ inclusions due to preexisting trenches at the interface ${ }^{26}$. No preexisting trenches were discovered on the surface of the SS, proposedly due to plastic deformation of grinding and polishing ${ }^{26}$. Formation of such trenches seems feasible due to the difference in the coefficients of thermal expansion between the three phases, associated with the AIFeMnSi alloy, with varying composition. The initiation may occur by dissolution of the surface until a preexisting trench between Phases II and III is reached, upon which the formation of a critical pitting solution is formed leading to the undercutting of Phase III. It should be noted again the 2-week immersion testing indicated that Phase III was the most corrosion resistant phase (Fig. 3a). 
(a)

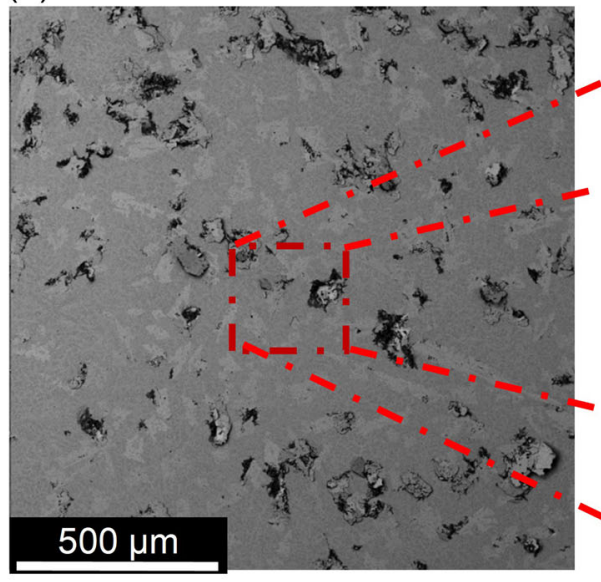

(b)

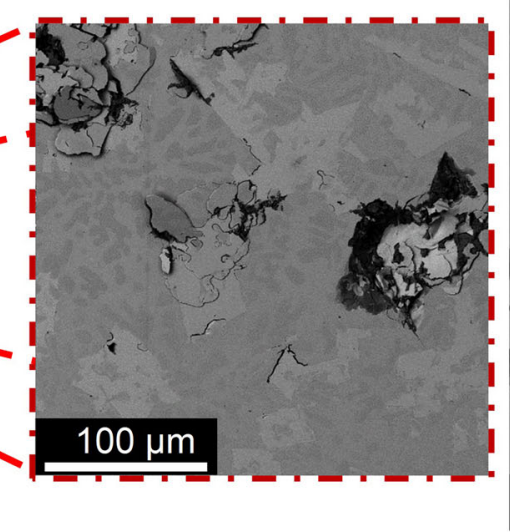

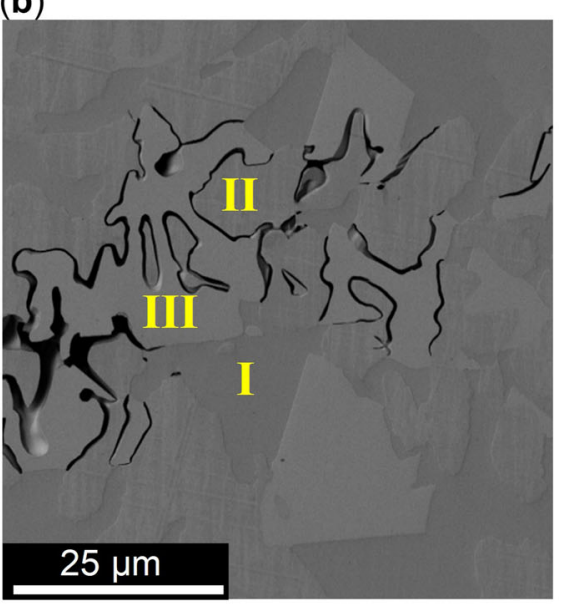

Fig. 8 BSE-SEM images of the AIFeMnSi alloy post $+400 \mathbf{m V}$ SCE potentiostatic conditioning in $0.6 \mathrm{M}$ NaCl. BSE-SEM images $(5 \mathrm{kV}$ accelerating voltage) of the AlFeMnSi alloy after a 10 min and $\mathbf{b} 30$ s of potentiostatic conditioning at $+400 \mathrm{mV}$ SCE in $0.6 \mathrm{M} \mathrm{NaCl}$.

XPS was performed on the AlFeMnSi alloy after potentiostatic conditioning (in the cathodic, passive, and transpassive regions) and $24 \mathrm{~h}$ immersion, to provide the chemical states and change in composition over the alloy's surface. The potentiostatic conditioning was performed, specifically, to gain insight into the corrosion mechanism of the AlFeMnSi alloy in $0.6 \mathrm{M} \mathrm{NaCl}$. Comparing the trends of the elements' concentrations, described above and seen in Figs. 4-7, the surface film is initially composed primarily of $\mathrm{Si}^{\mathrm{x}+}$ and $\mathrm{Al}^{\mathrm{x}+}$. However, at higher potentials, the ratio of $\mathrm{Si}^{\mathrm{x}+}$ increases, to where in the transpassive region, the surface film is comprised primarily of $\mathrm{Si}^{\mathrm{x}+}$ as well as a small fraction of remaining oxidized and unoxidized elements. In addition, at higher potentials, the chemical state of $\mathrm{Si}$ shifted-from a mixture of $\mathrm{SiO}_{2}$ and a $\mathrm{Si}$ containing complex oxide (such as $\mathrm{Al}_{2} \mathrm{SiO}_{5}{ }^{27}$ or $\mathrm{Fe}_{2} \mathrm{SiO}_{4}{ }^{28}$ ) to only $\mathrm{SiO}_{2}$ in the transpassive region, a potentially less protective/stable surface film ${ }^{29}$ (see Supplementary Fig. $5 d$ ). It should be noted, the potential existence of other complex oxides present in the surface film that overlap binding energies of species stated above, such as known complex oxides (e.g., $\mathrm{MnSiO}_{3}$ or $\mathrm{MnAl}_{2} \mathrm{O}_{4}{ }^{30}$ ) or unknown complex oxides ${ }^{12}$. Unlike the passive and cathodic regions, the transpassive region exhibited definitive accelerated dissolution between Phases II and III. The increase in oxidized Si and decrease in oxidized Al, found in the XPS results at increasing potential, may also be explained by the transpassive dissolution of the $\mathrm{Al}^{\mathrm{x}+}$ enriched layer, observed in $\mathrm{Al}-\mathrm{Mn}$ thin films ${ }^{31}$.

\section{Compositional analysis of the surface film layer using STEM-EDXS}

STEM-based mapping experiments (STEM and EDXS) were performed across the surface film interface of each phase within a specimen after $24 \mathrm{~h}$ immersion in $0.6 \mathrm{M} \mathrm{NaCl}$ to obtain higher spatial resolution information of the elemental distribution. The data from these experiments are shown in Supplementary Fig. 3 (Supplementary Notes 4), showing that the chemical composition of the surface film was dependent upon the underlying phase. Based on STEM-EDXS line profile experiments, the thickness of the surface film layer and the composition gradient of the different solute element across the surface film and into the matrix were estimated. The converged electron beam with an approximate probe size of $0.14 \mathrm{~nm}$ in STEM mode was scanned along 400 points with an approximate acquisition time of $1 \mathrm{~s}$ per point. The STEM images in Fig. 9 show that the surface film originates below the protective platinum $(\mathrm{Pt})$ cap (see Preparation of the crosssectional STEM sample in the "Methods" section), which is marked by the orange dashed line extending from the image to the line plots above. The dashed line coincides with $\mathrm{O}$ and $\mathrm{Al}$ peaks for Phases I-III, as shown in Fig. 9. Thickness of the oxide layer was measured by fitting the $O$ line profile data to a Gaussian-based peak fitting function, estimating the full width half maximum (FWHM). Thickness of surface film for each constituent phase was $\sim 1 / 2$ FWHM (Supplementary Notes 4$)^{32}$. The surface film layer thickness of the three phases was found to be approximately 2.25, 4.14, and $7.25 \mathrm{~nm}$ for Phase I, Phase II, and Phase III, respectively. Comparatively, the XPS results indicated a $10 \mathrm{~nm}$ surface film thickness overall, and the increased thickness can be explained by spontaneous oxidation. Al enrichment was observed in the top of the surface film for each phase, along with a corresponding depleted Al layer directly underneath the surface film (an indication of incongruent dissolution of the substrate/preferential dissolution of $\mathrm{Al}$ ). Incongruent dissolution with enrichment in the surface film has also been observed in other CCAs, such as AITiVCr (Al enrichment) ${ }^{20}$ and $\mathrm{Ni}_{38} \mathrm{Fe}_{20} \mathrm{Cr}_{22} \mathrm{Mn}_{10} \mathrm{Co}_{10}\left(\mathrm{Cr}\right.$ enrichment) ${ }^{33}$. Al content within the enriched layer was found to be highest in Phase II and lowest in Phase III. The Fe composition within the depleted Al layer increases by a small amount relative to the nominal matrix Fe composition. The ratios of maximum Fe content in the depleted Al layer compared to the nominal Fe content in the matrix were found to be 1.2, 1.13, and 1.07 for Phases I, II, and III, respectively. Si content within the matrix and within the depleted layer did not show any significant variation in Phases I and III. However, Si content in Phase II increased by 3 at.\% relative to the $\mathrm{Si}$ content in the matrix. For each phase, Mn content gradually decreased from the matrix to the depleted Al region followed by a sharp decrease at the oxide layer. The composition within the top of the surface film of each phase varied; the at.\% composition order of each phase was $\mathrm{Al}>\mathrm{Mn}>\mathrm{Si}>\mathrm{Fe}$ (Phase I), $\mathrm{Al}>\mathrm{Si}>\mathrm{Fe}>\mathrm{Mn}$ (Phase II), and $\mathrm{Si}>\mathrm{Al}>\mathrm{Mn}>\mathrm{Fe}$ (Phase III). Looking at the solute gradient across the surface film of each phase, the top of the surface atomic percentage of $\mathrm{Si}$ is the smallest for Phase II, which indicates a lesser amount of the potentially protective complex oxide, and therefore, possible preferential corrosion. In addition, the limited amount of oxygen found at the top of the surface film denotes a film composed of oxidized and unoxidized species.

Microstructural analysis and surface characterization of the equimolar AIFeMnSi alloy, using SEM, STEM, and XPS, revealed the formation of a complex surface film enriched in $\mathrm{Al}$ and $\mathrm{Si}$ (in particular, the stable form of a Si containing complex oxide), an underlying surface film of an enriched Al layer and a combination of oxidized and unoxidized species. The attainment of high 


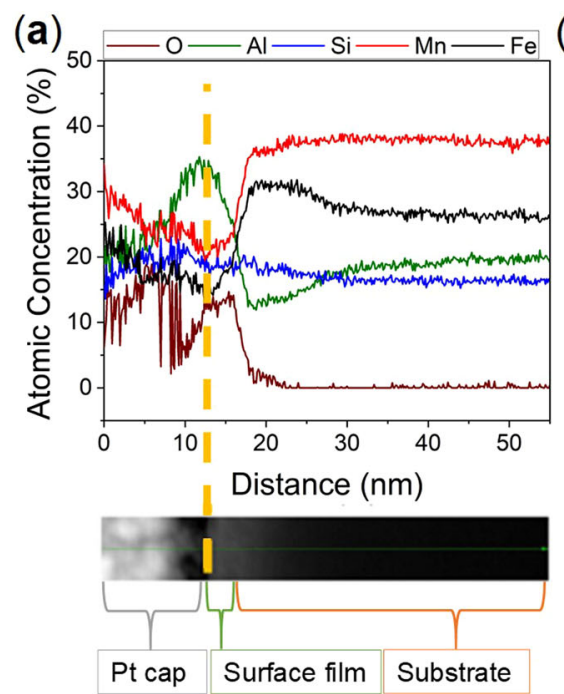

(b)
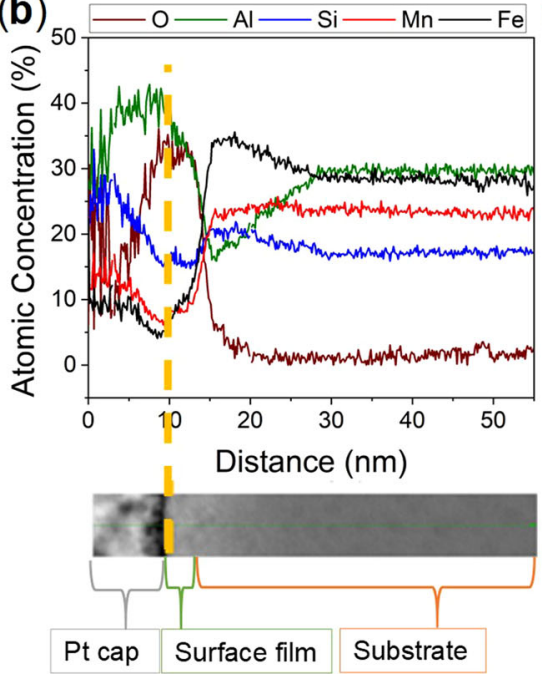

(c)

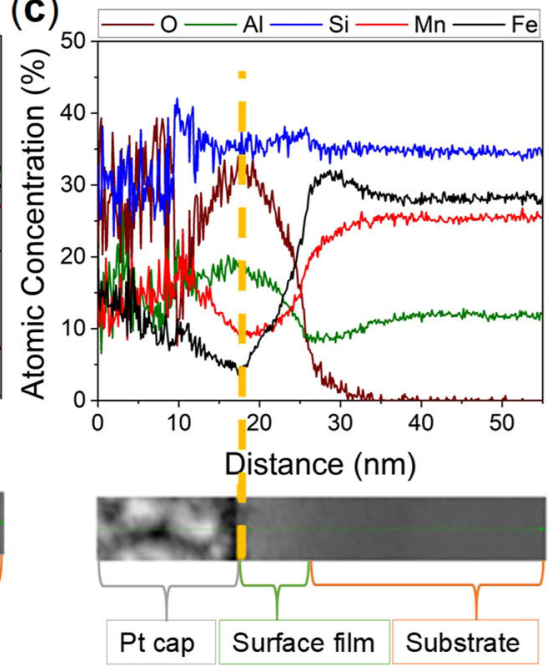

Fig. 9 STEM-EDXS line profiles and STEM images post $24 \mathrm{~h}$ immersion of the phases in the AIFeMnSi alloy in $0.6 \mathrm{M}$ NaCI. STEM-EDXS line profile (and corresponding STEM image) showing composition of the surface film upon the three phases that comprise the AlFeMnSi alloy microstructure (as noted in Fig. 1d) after $24 \mathrm{~h}$ immersion in $0.6 \mathrm{M} \mathrm{NaCl}$, a Phase I, b Phase II, and c Phase III. Specimens were prepared from site specific focused ion beam (FIB) milling.

corrosion resistance in a multiphase CCA comprised of low-cost alloying elements, is not only unique-it also sheds light on the notion that thermodynamic stability (as may be interpreted from equilibrium calculations, such as in the development of Pourbaix diagrams) is not a necessity for attaining high corrosion resistance. Such demonstrations of so-called dynamic passivity have also recently been revealed for other alloy systems, including $\mathrm{Mg}$ alloys $^{34}$.

Additional research is needed to further improve the applicability of the AlFeMnSi alloy, e.g., to further optimize the alloy composition or change the processing route. This is the focus of our ongoing research and is out of scope of the herein presented study.

\section{METHODS}

\section{Alloy production}

The AlFeMnSi alloy specimens studied herein were synthesized by the arc melting process. Metal pieces (with a purity greater than or equal to $99.9 \%$ ) were placed in a copper crucible in equimolar proportions, and arc melted in an inert argon environment. The synthesized alloy specimens were flipped at least thrice, and remelted multiple times in order to obtain a homogenous composition.

\section{Microstructural characterization}

SEM was performed using a Tescan Lyra 3 FIB-FESEM utilizing a $20 \mathrm{kV}$ accelerating voltage. Secondary electron and BSE modes were used to characterize the alloy microstructure. EDXS area mapping and point analysis were conducted to estimate the elemental distribution and approximate composition of phases. SEM and EDXS analysis were performed on six individual specimens to verify the repeatability of the alloy production process and to ensure reproducibility. Specimens for SEM and EDXS analysis were metallographically prepared to a $0.05 \mu \mathrm{m}$ surface finish using a colloidal silica suspension and ultrasonically cleaned in ethanol.

\section{Hardness measurements}

A Wilson Tukon 1202 Vickers hardness tester was used to measure Vickers hardness. Specimens were prepared by grinding to a 1200 grit SiC paper surface finish, and then a load of $50 \mathrm{~g}$ was applied with a dwell time of $10 \mathrm{~s}$, for multiple measurements $(>10)$, in order to obtain average hardness values for each phase present in the alloy.

\section{Electrochemical testing}

PDP testing was utilized to electrochemically investigate the corrosion behavior and was performed on the six different specimens of same alloy composition. Specimens for corrosion testing were ground to a 1200 grit $\mathrm{SiC}$ paper surface finish. A conventional three-electrode electrochemical flat cell was utilized, employing a saturated calomel reference electrode (SCE) and Pt mesh counter electrode. All tests were conducted in naturally aerated $0.6 \mathrm{M} \mathrm{NaCl}$ solution with a VMP300 potentiostat (Biologic). The open-circuit potential (OCP) was stabilized for an hour, followed by PDP with a potential sweep rate of $0.167 \mathrm{mV} / \mathrm{s}$.

EIS was conducted in $0.6 \mathrm{M} \mathrm{NaCl}$. The OCP was stabilized for an hour, followed by measurements employing a frequency ranging from $100 \mathrm{kHz}$ to $10 \mathrm{mHz}$ with an amplitude of $10 \mathrm{mV}$. Measurements were carried out using a Gamry ${ }^{\circledR}$ Reference 600 potentiostat, and spectra were fitted with ZView $^{\circledast}$ software.

\section{Immersion testing}

Immersion tests were carried out in $0.6 \mathrm{M} \mathrm{NaCl}$ for a period of $24 \mathrm{~h}$ and 2 weeks. Prior to immersion testing, specimens were metallographically prepared to a $0.05 \mu \mathrm{m}$ surface finish, with the final step employing a colloidal silica suspension, followed by ultrasonic cleaning in ethanol and rinsing with deionized water. After immersion, specimens were thoroughly rinsed with deionized water to remove $\mathrm{NaCl}$, and SEM imaging was carried out using a $5 \mathrm{kV}$ accelerating voltage.

\section{Potentiostatic conditioning}

In order to assess the surface films upon AlFeMnSi specimens for different (electrochemical) exposure conditions, potentiostatic holds were performed in the cathodic, passive, and transpassive regions. Prior to electrochemical exposure in $0.6 \mathrm{M} \mathrm{NaCl}$, specimens were prepared to a $0.05 \mu \mathrm{m}$ surface finish and cleaned with the same method described above.

\section{X-ray photoelectron spectroscopy}

XPS was performed using a $\mathrm{PHI}{ }^{\circledR}$ VersaProbe 5000 XPS Microprobe to study the surface of the specimens after $24 \mathrm{~h}$ immersion and potentiostatic conditioning in $0.6 \mathrm{M} \mathrm{NaCl}$ solution. Survey spectra were obtained with a band pass energy of $117.4 \mathrm{eV}$ and a scan area of $200 \mu \mathrm{m}$, while highresolution spectra were obtained with a band pass energy of $11.75 \mathrm{eV}$ and a scan area of $200 \mu \mathrm{m}$. Survey spectra were only performed to identify elements present on the surface, while high-resolution spectra were used in quantification of atomic concentrations. The total vacuum chamber pressure was $10^{-8}$ torr, and the depth profiling was conducted using a floating column argon ion gun with the impact energy of $2 \mathrm{keV}$. Binding 
energies were calibrating with the Fe peak at $706.7 \mathrm{eV}$. The high-resolution spectra analysis was conducted with $\mathrm{PH}{ }^{\circledR}$ MultiPak software.

\section{Preparation of the cross-sectional STEM sample}

A focused gallium ion $\left(\mathrm{Ga}^{+}\right)$beam scanning electron microscope (FIB-SEM), Helios NanoLab ${ }^{T M}$, was used to prepare site specific specimens from a region that consists of the three constituent phases of the CCA. Using the electron beam, a protective layer of Pt was deposited prior to ion beam deposition of a thicker Pt cap layer, in order to protect the surface filmformed after $0.6 \mathrm{M} \mathrm{NaCl}$ immersion-from ion beam damage. The $\mathrm{Ga}^{+}$ion beam was used to mill trenches on either side of the Pt cap to remove a prethinned lamella from the bulk sample. The prethinned lamella was transferred onto a Cu Omniprobe ${ }^{\mathrm{TM}}$ TEM grid and then thinned to electron transparency. The $\mathrm{Ga}^{+}$ion beam current was iteratively reduced from $0.28 \mathrm{nA}$ to $28 \mathrm{pA}$, while maintaining the accelerating voltage constant at $30 \mathrm{kV}$.

\section{STEM and EDXS}

The cross-sectional samples were analyzed using a Thermo Scientific ${ }^{\mathrm{TM}}$ Titan scanning transmission electron microscope operated at $300 \mathrm{kV}$ and equipped with a Super $X^{\mathrm{TM}}$ energy-dispersive $X$-ray spectrometer. STEM-EDXS mapping and line profile experiments were performed across the surface film interface. The EDXS data obtained were post processed and quantified using the Bruker ESPRIT software.

\section{DATA AVAILABILITY}

The data that support the findings of this study are available from the corresponding authors upon reasonable request.

Received: 28 October 2020; Accepted: 1 February 2021; Published online: 19 March 2021

\section{REFERENCES}

1. Sibley, S. F. \& Butterman, W. C., Staff. Metals recycling in the United States. Resour. Conserv. Recycl. 15, 259-267 (1995).

2. Marcus, P. On some fundamental factors in the effect of alloying elements on passivation of alloys. Corros. Sci. 36, 2155-2158 (1994).

3. Sugimoto, K. \& Sawada, Y. The role of alloyed molybdenum in austenitic stainless steels in the inhibition of pitting in neutral halide solutions. Corrosion 32, 347-352 (1976).

4. Wu, Z., Bei, H., Pharr, G. M. \& George, E. P. Temperature dependence of the mechanical properties of equiatomic solid solution alloys with face-centered cubic crystal structures. Acta Mater. 81, 428-441 (2014).

5. Jensen, J. K. et al. Characterization of the microstructure of the compositionally complex alloy Al1Mo 0.5Nb1Ta0.5Ti1Zr1. Scr. Mater. 121, 1-4 (2016).

6. Kuznetsov, A. V., Shaisultanov, D. G., Stepanov, N., Salishchev, G. A. \& Senkov, O. N. Superplasticity of AlCoCrCuFeNi high entropy alloy. in Materials Science Forum, Vol. 735, 146-151 (Trans Tech Publications, 2013).

7. Gludovatz, B. et al. A fracture-resistant high-entropy alloy for cryogenic applications. Science 345, 1153-1158 (2014).

8. Zhang, Y. et al. Microstructures and properties of high-entropy alloys. Prog. Mater. Sci. 61, 1-93 (2014).

9. Qiu, Y., Thomas, S., Gibson, M. A., Fraser, H. L. \& Birbilis, N. Corrosion of high entropy alloys. npj Mater. Degrad. 1, 15 (2017).

10. Lu, P. et al. Computational design and initial corrosion assessment of a series of non-equimolar high entropy alloys. Scr. Mater. 172, 12-16 (2019).

11. Raza, A., Abdulahad, S., Kang, B., Ryu, H. J. \& Hong, S. H. Corrosion resistance of weight reduced AlxCrFeMoV high entropy alloys. Appl. Surf. Sci. 485, 368-374 (2019).

12. Gerard, A. Y., Lutton, K., Lucente, A., Frankel, G. S. \& Scully, J. R. Progress in understanding the origins of excellent corrosion resistance in metallic alloys: from binary polycrystalline alloys to metallic glasses and high entropy alloys. Corrosion 76, 485-499 (2020).

13. Qiu, Y., Gibson, M. A., Fraser, H. L. \& Birbilis, N. Corrosion characteristics of high entropy alloys. Mater. Sci. Technol. 31, 1235-1243 (2015).

14. Esquivel, J., Murdoch, H. A., Darling, K. A. \& Gupta, R. K. Excellent corrosion resistance and hardness in Al alloys by extended solid solubility and nanocrystalline structure. Mater. Res. Lett. 6, 79-83 (2018).
15. Shi, Y., Collins, L., Balke, N., Liaw, P. K. \& Yang, B. In-situ electrochemical-AFM study of localized corrosion of AlxCoCrFeNi high-entropy alloys in chloride solution. Appl. Surf. Sci. 439, 533-544 (2018).

16. Shi, Y. et al. Corrosion of AlxCoCrFeNi high-entropy alloys: Al-content and potential scan-rate dependent pitting behavior. Corros. Sci. 119, 33-45 (2017).

17. Shi, Y. et al. In-situ visualization of corrosion behavior of AlxCoCrFeNi highentropy alloys during electrochemical polarization. J. Alloy. Compd. 844, 156014 (2020).

18. Qiu, Y. et al. A lightweight single-phase AlTiVCr compositionally complex alloy. Acta Mater. 123, 115-124 (2017).

19. Qiu, Y. et al. Microstructure and corrosion properties of the low-density single-phase compositionally complex alloy AITiVCr. Corros. Sci. 133, 386-396 (2018).

20. Qiu, Y. et al. A surface study of the native oxide upon a compositionally complex alloy. Corrosion 74, 1312-1317 (2018).

21. Qiu, Y. et al. Real-time dissolution of a compositionally complex alloy using inline ICP and correlation with XPS. npj Mater. Degrad. 4, 1-6 (2020).

22. Scully, J. R. et al. Controlling the corrosion resistance of multi-principal element alloys. Scr. Mater. 188, 96-101 (2020).

23. Huang, X., Miao, J. \& Luo, A. A. Lightweight AICrTiV high-entropy alloys with dualphase microstructure via microalloying. J. Mater. Sci. 54, 2271-2277 (2019).

24. Fu, X., Schuh, C. A. \& Olivetti, E. A. Materials selection considerations for high entropy alloys. Scr. Mater. 138, 145-150 (2017).

25. Zoltowski, P. On the electrical capacitance of interfaces exhibiting constant phase element behaviour. J. Electroanal. Chem. 443, 149-154 (1998).

26. Lillard, R. S., Kashfipour, M. A. \& Niu, W. Pit propagation at the boundary between manganese sulfide inclusions and austenitic stainless steel 303 and the role of copper. J. Electrochem. Soc. 163, C440 (2016).

27. Wagner, C. D., Six, H. A., Jansen, W. T. \& Taylor, J. A. Improving the accuracy of determination of line energies by ESCA: Chemical state plots for siliconaluminum compounds. Appl. Surf. Sci. 9, 203-213 (1981).

28. Qiang, R., Leong, A., Zhang, J. \& Short, M. P. Corrosion behavior of Fe-Cr-Si alloys in simulated PWR primary water environment. J. Nucl. Mater. 526, 151735 (2019)

29. Gallup, D. L. Aluminum silicate scale formation and inhibition: scale characterization and laboratory experiments. Geothermics 26, 483-499 (1997).

30. Grosvenor, A. P., Bellhouse, E. M., Korinek, A., Bugnet, M. \& McDermid, J. R. XPS and EELS characterization of $\mathrm{Mn2SiO} 4, \mathrm{MnSiO} 3$ and MnAl2O4. Appl. Surf. Sci. 379, 242-248 (2016).

31. Mraied, H., Cai, W. \& Sagüés, A. A. Corrosion resistance of Al and Al-Mn thin films. Thin Solid Films 615, 391-401 (2016).

32. Hamada, E. et al. Direct imaging of native passive film on stainless steel by aberration corrected STEM. Corros. Sci. 52, 3851-3854 (2010).

33. Gerard, A. Y. et al. Aqueous passivation of multi-principal element alloy

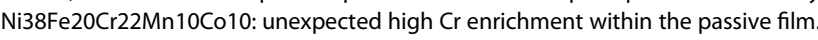
Acta Mater. 198, 121-133 (2020).

34. $\mathrm{Xu}, \mathrm{W}$. et al. A high-specific-strength and corrosion-resistant magnesium alloy. Nat. Mater. 14, 1229-1235 (2015).

\section{ACKNOWLEDGEMENTS}

R.K.G. and N.B. acknowledge support from the Office of Naval Research under the contract ONR: N00014-17-1-2807 with Dr Airan Perez as program officer. The authors would like to thank Jonathan Geiser for assistance with hardness and PDP data collection. STEM and EXDS data were acquired at the Center for Electron Microscopy and Analysis at the Ohio State University.

\section{AUTHOR CONTRIBUTIONS}

S.P.O. carried out the experimental studies, which included the corrosion tests, SEMEDX, and XPS. J.C. carried out XPS. S.V. conducted TEM. All authors contributed in drafting or revising the paper. R.K.G. and N.B. supervised the study.

\section{COMPETING INTERESTS}

The authors declare no competing interests.

\section{ADDITIONAL INFORMATION}

Supplementary information The online version contains supplementary material available at https://doi.org/10.1038/s41529-021-00158-5.

Correspondence and requests for materials should be addressed to R.K.G. 
Reprints and permission information is available at http://www.nature.com/ reprints

Publisher's note Springer Nature remains neutral with regard to jurisdictional claims in published maps and institutional affiliations.

c) Open Access This article is licensed under a Creative Commons Attribution 4.0 International License, which permits use, sharing, adaptation, distribution and reproduction in any medium or format, as long as you give appropriate credit to the original author(s) and the source, provide a link to the Creative Commons license, and indicate if changes were made. The images or other third party material in this article are included in the article's Creative Commons license, unless indicated otherwise in a credit line to the material. If material is not included in the article's Creative Commons license and your intended use is not permitted by statutory regulation or exceeds the permitted use, you will need to obtain permission directly from the copyright holder. To view a copy of this license, visit http://creativecommons. org/licenses/by/4.0/.

(c) The Author(s) 2021 